\title{
Developing a relationship with nature and place: the potential role of forest school
}

\author{
F. HARRIS
}

Environmental Education Research

\section{0-0002-6649-9233 Frances Harris 1}

${ }_{1}$ School of Education, University of Hertfordshire, Hatfield, UK CONTACT Frances Harris f.harris@herts.ac.uk School of Education, University of Hertfordshire, Mosquito Way, Hatfield AL10 9EU, UK

\section{Abstract}

Outdoor learning provides an opportunity for schools to foster children's engagement with nature. This paper focusses on forest school practitioners' perceptions of children's development of a relationship with nature and the place where forest school occurs, through interviews with forest school activity leaders. Reflecting on literature, the analysis of interviews sought to identify the processes through which attachment to place or connection to nature occurs. The findings suggest that through regular and repeated activities in a natural setting at forest school, children become more relaxed, overcome any fears, have fun, connect with nature as they come to know it better, and develop an affinity for the location. Further, they develop a sense of ownership and concern for the forest school setting and desire to protect it. For some forest school practitioners, fostering a relationship with nature and place, and developing proenvironmental behaviour, is a fundamental part of their practice. 
Keywords: Forest school ; nature connection ; place

attachment ; environmental education ; outdoor learning

\section{Introduction}

Amid increasing concerns about children's disconnection from nature (Louv 2005; England Marketing 2009; Gill 2005; Sustainable Development Commission 2011), the role of schools in providing opportunities for children to learn about nature and the outdoors through outdoor learning is increasingly important (Tugurian and Carrier 2017; Sjöblom and Wolff 2017). Assessments of the time children spend outdoors in natural environments show that significant groups of the population spend little time outdoors (Hunt, Burt, and Stewart 2015). This reduction in interaction with nature coincides with a growing sense of urgency concerning global environmental problems such as climate change and biodiversity decline. Concerns have been expressed that if children do not know of and appreciate the natural world they are less likely to care for it and so adopt pro-environmental behaviours (Zylstra et al. 2014; Beery and WolfWatz 2014). It is suggested that time children spend at school could be used to provide opportunities for children to be outdoors in nature (Adams and Savahl 2017) and nurture an interest in and ethic of care for nature (Tugurian and Carrier 2017; Hart 1994; Sjöblom and Wolff 2017).

Forest school stands out as an activity which enables children to visit natural sites and engage with nature on a regular basis within the school timetable. A growing body of research indicates that the impacts of forest school may be wide-ranging, from increasing exercise through learning 
about nature, developing social skills, and improving self-esteem (see for example Knight 2009; Lovell and Roe 2009; Maynard 2007; O'Brien and Murray 2007; Swarbrick, Eastwood, and Tutton 2004). The UK's Forest School Association identifies six guiding principles of forest school, which include the aim to "support the development of a relationship between the learner and the natural world .... through regular personal experiences in order to develop long term environmentally sustainable attitudes and practices" (FSA 2020). Only a few studies have specifically examined whether this goal is being met (Turtle, Convery, and Convery 2015; Smith, Dunhill, and Scott 2018; Cumming and Nash 2015).

This paper focusses on forest school practitioners' perceptions of children's development of a relationship with nature and the place where forest school occurs. This paper investigates the experiences of a community of forest school practitioners. Interviews assessed their perceptions of children's experiences of forest school. The paper focusses specifically on practitioners' perceptions of whether children developed a relationship to nature through an attachment to the place or connection to the nature where forest school occurs; whether children return to forest school sites outside of sessions, and the potential implications of this for development of pro-environmental behaviours in the longer term.

\section{Encounters with nature and environmental behaviour}

Several studies suggest that individual encounters and experiences with nature can provide a pathway to environmental behaviour, and that time 
spent in nature when young can have lasting impact on children's attitudes to the natural environment through their lives (Beery and Wolf-Watz 2004; Chawla 2001; Chawla and Cushing 2007; Cheng and Monroe 2012; Collado et al. 2015; Ernst and Theimer 2011; Kellert 2005; Kudryavtsev, Stedman, and Krasny 2012; Öhman and Sandell 2016; Palmer et al. 1999; Pretty et al. 2009).

Together this body of work suggests formative experiences in nature enable the development of learning and interest in nature which then lead to a concern for the environment, and actions to conserve it. It is believed that development of ties with places, through positive experiences, will inspire children to learn about the environment, and ultimately to want to protect it. In their review, Kudryavtsev et al. (2016) argue that people will want to protect places that are meaningful to them, and note this refers to cultural and social meaning, as well as ecological meaning. It is also believed that the younger a child is during encounters with nature, the greater the likelihood that they will develop a connection to the natural environment (White and Stoecklin 2008) and that place attachments formed in childhood are stronger than those formed in later life (Morgan 2010). Research shows that young children conceptualise nature in different ways, including as simply natural things, as a provider and source of food, and as a place related to their identity (Spiteri, Higgins, and Nicol 2020). Further, children can develop an ethos of care for the environment from a very young age, including those within education at EYFS / Kindergarten / nursery stages (Elliot and Krusekopf 2018; Spiteri, Higgins, and Nicol 2020). This has implications for how they view 
nature, how they develop a relationship with nature, and the nature of that relationship: whether it be one of appreciation, curiosity, utilitarian value / provisioning, or compassion and care.

Two areas of research which suggest a possible route towards the development of a relationship with the natural world are place attachment, and connection to nature.

Much has been written about the concept of place attachment, with differing definitions reflecting on the multi-dimensionality of this concept (Scannell and Gifford 2010). The fairly simple definition "the bonding of people to places" (Altman and Low 1992 a cited in Manzo 2003) has been investigated in more detail to reveal debates about whether it relates to a specific place, or a type of place (e.g. a specific wood, or woods in general (Harrington 2018)) and also the nature of that relationship: whether it is based on the restorative aspects of a place (Kaplan and Kaplan 1989); a commitment to return, ecological stewardship, habit and familiarity (Manzo 2003); a refuge from daily routine (Hartig, Mang, and Evans 1991); a place to relax (Korpela et al. 2001); or a place to belong (Manzo 2003). Scannell and Gifford (2010) define place attachment as "bonding that occurs between individuals and their meaningful environments". Within this, they identify diversity within definitions, some referring to an emotional bond, or to place meaning and attachment (leading to use of public spaces) and others referring to attachments to neighbourhoods (leading to a reduction in incivility) and to place attachment as being a possible factor which contributes to an understanding of pro-environmental behaviour. Other authors also identify multiple definitions of the concept and 
categories of place attachment (Morgan 2010). In their review, Scannell and Gifford (2010) identify a tripartite model of place attachment, which considers the person (who is attached, an individual or a group); the process of how they are attached to the place (affective, cognitive or behavioural attributes); and the nature of the place, or what they are attached to (a physical space, or a socially symbolic space).

Chawla defines children's attachment to place, stating "children are attached to a place when they show happiness at being in it and regret or distress at leaving it, and when they value it not only for the satisfaction of physical needs but for its own intrinsic qualities" (Chawla $1992 \mathrm{p} \mathrm{64)}$. Raymond, Brown, and Weber (2010) identify the role of a physical setting in creating a specific venue for social experiences, and the subsequent social bonds and relationships (with others, or with a specific place) that form, stating that "the nature of the physical setting provides the container for social experiences and the bonds which form through these experiences". They also identify the role of the community in providing the filter through which individuals develop and identify with place. Their model of place attachments is structured around personal, community and natural environment contexts. They argue that place attachment related to natural aspects of a place impacts on environmental identity, whereas emotional attachment to places relates to pro-environmental behaviours. As Tuan 1977, (cited in Manzo 2003) states "space evolves into place as we come to know it better and endow it with value".

In their extensive review, Kudryavtsev, Stedman, and Krasny (2012) distinguish between place attachment and place meaning which they argue 
together result in a sense of place. Lewicka (2011) notes that of the three components of Scannell and Gifford's model, research has focused more on the person becoming attached to place, rather than the place people become attached to, or the process. In her review, it is clear that much of the research has focussed on attachment to urban places, rather than nature, and much of the research focusses on adults.

Both Lewicka (2011) and Morgan (2010) recognise the need for greater understanding of the processes through which attachment to place occurs. Lewicka (2011) concludes that a theory of place attachment is needed which could identify "the processes through which people for their meaningful relationships with places". Morgan (2010) suggests a model driven by exploration and assertion which begins with place arousal (fascination / excitement), followed by place behaviour (exploration, play) and then leads to positive affect. Manzo (2003) states repeated and direct experience in places, whether positive or negative, create pivotal moments, and feelings of safety, resulting in place meaning. Southon et al. (2017) show that locations were better appreciated if people had visited frequently and were able to identify plants. Schebella et al. (2017) study of what draws people to their favourite places identified multiple factors: the setting, the activity and the benefit derived from it, and recognised "fascination" as the most important. Laaksoharju and Rappe (2017) noted that trees provided a variety of ways for children to become connected to place. Wells and Lekies (2006) suggest that experiences in woods as children will encourage people to return as adults. 
Connection to nature is defined variously as "a construct that refers to an individual's subjective sense of their relationship with the natural world" ( $p$ 8. Lumber, Hunt, Richardson, and Harvey 2017), and "the mix of feelings and attitudes that people have towards nature" (RSPB 2015). Connection is achieved through affective engagement (activities involving all senses), cognitive engagement (recognising, identifying, naming) and physical engagement (touching, being in nature, using or making). The pathways for connection to nature are summarised as contact, emotion, compassion, meaning and beauty (Lumber, Richardson, and Sheffield 2017).

Gosling and Williams (2010) suggest connectedness to nature leads to biospheric concern which then leads to pro-environmental behaviour. An important distinction should be made between cognitive interest in nature, and emotional affinity for nature (Kals, Schumacher, and Montada 1999) with several studies concluding that it is the experience in the natural environment which results in connection, more than learning about the natural environment (Kals, Schumacher, and Montada 1999; Otto and Pensini 2017). Beery and Wolf-Watz (2014) discuss the importance of place-based encounters with nature for impacting on environmental behaviour.

There are concerns that without experiencing and knowing nature, children will not appreciate what it is, its potential value (in much more than a monetary sense), and therefore will not be concerned about its potential loss. Opportunities to experience nature at a personal, visceral level are increasingly rare for many children, especially those who live in urban areas, without gardens, and with limited opportunity for free play outdoors. 
Children's access to, and time spent in nature, varies. Access may depend on proximity and/or cost to get to it, but also safety, parental concerns, and time available among the demands of school and after-school clubs and activities (Holloway and Pimlott-Wilson 2014; Malone 2007). School-based environmental education and outdoor learning initiatives offer opportunities for children to access experiences in natural environments (Hunt, Burt, and Stewart 2015; Grimm et al. 2011; Kudryavtsev, Stedman, and Krasny 2012; Otto and Pensini 2017). Öhman and Sandell (2016) view outdoor learning in nature as fostering pro-environmental behaviour. Encouraging engagement with the environment is seen as important in educational settings, even from a young age. It is believed there is a role for nature kindergartens in developing a life-long relationship with the outdoors and this is identified within policy documents relating to nature kindergartens in

Sweden (Ärlemalm-Hagsér 2013), Canada (Elliot and Krusekopf 2018) and Australia (Christiansen et al. 2018).

This brief review of the literature on attachment to place and connection to nature suggests a variety of processes which might occur while children repeatedly engage in forest-based outdoor learning, relating to emotions, learning about nature, meaning-making, compassion and behaviour.

\section{Forest school}

There is a long history of forest education (Grimm et al. 2011), with many non-formal programmes of forest education developed to support formal schooling. Some are focussed on nature kindergartens, while others aim toward primary school and lower secondary school children. Some have a 
particular focus on ecological knowledge (e.g. Marks et al. 2017), whereas others take a broader view of learning, and include a desire to promote eco-sensitive attitudes (Grimm et al. 2011).

In the UK, forest school is a growing movement offering children regular time in nature at a specific place, so becoming both forest-based and place-based outdoor learning. Although school based, it is generally separate from the national curriculum and so non-formal or extra-curricular (Grimm et al. 2011). One of the 6 principles of forest school states explicitly that forest school aims "to support the development of a lifelong relationship between the learner and the natural world" and the Forest School Association elaborates this as "to foster a relationship with nature through regular personal experiences in order to develop long-term, environmentally sustainable attitudes and practices in staff, learners and the wider community." (FSA 2020).

At forest school children participate in regular visits to natural (ideally woodland) areas to engage in learning through play-based activities (O'Brien and Murray 2007; Blackwell 2009) such as den building, fire lighting, campfire cooking, nature collecting, naming and identifying plants and animals, and nature art and craft. Children attend forest school on a weekly or biweekly basis which enables them to return to the site. While it is possible to link forest school to the national curriculum, it is seen as an 'alternative pedagogy' (Waite and Goodenough 2018) and a learning space free of the constraints of the national curriculum (Harris 2018). While widely adopted, it is not without its critics, centring around the drive within the industry to standardise forest school (Leather 2018); the capacity of a 
relatively short forest school training course to equip new forest school leaders to deliver forest school well (Morgan 2018); and the 'deforestation' of forest school as it is adapted to schools grounds and less wooded spaces (Morgan 2018). As attempts have been made by the UK forest school movement to share the approach with other countries, researchers have questioned the relevance of the forest school approach when exported to other countries and school systems via a "drag and drop" approach (Lloyd, Truong, and Gray 2018, see also Elliot and Krusekopf 2018) which serves as a reminder of the importance of the place based aspect of forest school.

Forest school sessions are led by leaders who have been trained in accredited courses to become level III forest school leaders. The training involves a mixture of learning about child development, managing children's behaviour, bush craft, nature identification, woodland management and health and safety. Forest school leaders may be teachers or teaching assistants, or they may be forest school leaders who work for environmental education or environmental conservation organisations and are hired by the school to lead sessions. Some schools have sufficient and appropriate grounds to enable forest school sessions to be led on site. Other schools make arrangements to travel to an appropriate location way from the school site. Due to the regular and repeated nature of forest school sessions any forest school site needs to be relatively close to the school.

Research on forest school has been varied as forest school sits at the centre of several different initiatives relating to children's education, well- 
being and environment. Thus research has focused on learning through play and child led learning; the development of team working and social skills; engaging with risk, challenge and adventure; reconnecting children with nature; outdoor learning; and levels of physical activity as children attend forest school (Harris 2018). There has been less research on whether forest school impacts on how children relate to and care for the settings in which they attend forest school or their longer-term views of the environment. There has been speculation that forest school might encourage children towards pro-environmental behaviours. Research on learning at forest school has identified that engagement with nature is a key outcome (Harris 2017). However, there are only a few papers so far focusing on children's development of a relationship with the environment through forest school (e.g. Cumming and Nash 2015; Smith, Dunhill, and Scott 2018; Turtle, Convery, and Convery 2015). Several studies note how children develop a sense of confidence as they come to know their forest school site (Massey 2005; Murray 2003; O’Brien 2005) with children developing a "sense of place" (Davis and Waite 2005) and proenvironmental attitudes (Turtle, Convery, and Convery 2015). This paper reports on the perceptions of forest school leaders concerning children's sense or development of attachment to place, and ethos of care, and proenvironmental behaviours, through attending forest school. It asks specifically about children's development of a connection to nature or attachment to place while attending forest school, and whether this is demonstrated as an ethos of care and pro-environmental behaviours.

\section{Method}


This empirical research takes an inductive approach with the aim of theory building, using qualitative methods across two phases of research. Prior to each phase of research, the protocol was approved through the University's ethics committee.

In Phase 1, an ethnographic approach was used, involving observation of children at sessions. This method has also been used in other studies of children at forest school (Tiplady and Menter 2020; Cudworth 2020). 71 children from an English primary school were observed as they attended forest school. The group was divided into 6 groups of approximately 12 children, with each group attending forest school for one half-term as an 'enrichment activity' on Friday afternoons. Groups were drawn from across the school, with children ranging from age 5-11 in each group of 12 . Working with the head teacher, all parents were informed of the research and asked to give permission for their children to be involved in the study. Children of parents who did not want their children to be involved could still attend forest school sessions. Observations were made at each session, and at the end of each half term the observations from the 6 sessions were collated and reviewed.

This initial phase of research served to identify several broad areas for further research, such as: What were children learning at forest school? How did the outdoor learning space influence the sessions? How did children respond to the sessions?

A challenge of phase 1 was that the results were derived from children attending a single, small, primary school. It was decided to broaden the scope of the research to cover a wider range of children, schools, locations 
and forest school leaders. Therefore, research in Phase 2 involved substantially different methods. It was decided to move away from participant observation and carry out research with forest school practitioners.

Many forest school practitioners meet regularly in "cluster groups" which enable them to share best practice or engage in continuing professional development activities. Through their training and the cluster groups, they are encouraged to be 'reflective practitioners' (Schon 1983) to deepen their understanding of forest school. As a community of practice (Wenger 1998) they hold a wealth of experience resulting from leading multiple sessions with many cohorts of children, and have contributed to some research studies (e.g. Tiplady and Menter 2020; Cudworth 2020); and played a role as conduits of evidence (Waite and Goodenough 2010), drawing on their experience of leading multiple cohorts of children through many forest school sessions. It is acknowledged that forest school practitioners are likely to hold a more positive stance towards forest school, and this is a source of potential bias in the research. However, this needs to be balanced against the need to conduct research with those who have had training in, and extended experience of, forest school, and understand the ethos of forest school.

Phase 2 drew on the results of Phase 1 which, along with a further literature review, informed the development of research questions and a topic guide for semi-structured interviews. The aim was to interrogate the experiential knowledge (both positive and negative) of forest school practitioners. Interviews were conducted with 20 forest school practitioners. 
Practitioners were identified through the Forest Education Initiative's cluster groups of forest school leaders. Interviewees were recruited from a sampling frame of 5 forest school cluster groups (encompassing 54 forest school leaders). In order to be interviewed, forest school leaders had to have been qualified for a minimum of 3 years, and have led more than 20 sessions, focussing on children in mainstream primary schools. Most, in practice, had exceeded this. The 20 forest school practitioners interviewed (13 women, 7 men) came from urban (5), rural (7) and peri urban (8) areas (the home counties, surrounding London). 13 worked for independent companies offering forest school activities, 5 worked with education councils or environmental trusts, and 2 were teachers based at schools. These practitioners answered the interview questions drawing on their experience of leading forest school sessions at multiple schools and sites, for a variety of year groups, over many years. Interviews lasted approximately 25 minutes and were conducted by telephone. The aim of the interviews was to interrogate their experiential knowledge, using a semi-structured interview topic guide, support by probing questions to further explore their answers. Interviews were recorded and then transcribed.

Data analysis followed guidance from Braun and Clarke (2013) and is similar to the examples of Ärlemalm-Hagsér (ㅁ13), Kemp (2020), Cumming and Nash (2015) and Tiplady and Menter (2020). The researcher was immersed in the data through reading all the transcripts of the interviews. A first stage of coding was guided by the initial semi-structured interview themes, and further themes identified during immersion in the 
data. After the initial coding, a further phase of analysis and sub-coding took place, to identify sub-themes emerging form the data. The process is summarised in Figure 1. As this is a single-authored study, initial coding and subsequent sub-coding was verified by an independent researcher who accessed the original transcripts of the interviews, and the sub-coding and independently confirmed the themes and sub-themes identified.

\section{Figure 1. Outline of the phases of research indicating process of data} analysis.

Phase 1: Ethnographic study via observation of forest school sessions

- Observation of 6 groups of approx. 12 children attending forest school session (total 71)

- Review and reflection after each session, each half term, and at end of school year.

- Identification of broad research questions for further detailed research

- Identification of topics for interview schedule for use in Phase 2

Phase 2: Interrogation of practitioners' experiential knowledge

- Recruitment of sample of 20 Forest School Practitioners from sample frame of Forest School Cluster group members.

- $1: 1$ semi-structured telephone interviews

- Transcription of interviews

- Immersion in data to reflect on topic guide and identify major coding themes

- Coding according to themes

- Interrogation of transcripts according to each theme

- Identification sub-themes and further coding

- Identification of illustrative quotes for use in paper

Many themes were collated and the results of the analysis of some themes have already been published in papers focussing on learning at forest school (Harris 2017) and outdoor learning spaces (Harris 2018). This paper 
focusses on practitioners' responses to questions about how children reacted to the experience of forest school, whether they engaged with nature, and whether children developed a relationship with nature and the woods, or more specifically, a relationship with place.

\section{Results and discussion}

17 of the 20 forest school practitioners interviewed commented on children developing a relationship with nature or with the woods, an ethos of care, and pro-environmental behaviours, with their comments relating to the subthemes outlined below.

\section{Overcoming fear}

Forest school practitioners were reflecting on their experiences with children from many schools, regions and backgrounds. Some children may have had previous experiences in outdoor and woodland areas, but for others, going to woodland areas may have been new. They may have had positive or negative experiences and memories of time spent in natural spaces. Some practitioners noted that initially, many children are afraid of the forest school site.

"I think it becomes less threatening to them. I think a lot of children initially when they come into sorest school are quite frightened by the outside. I think that comes from the sort of background. I mean, most of the children we work with come from the inner city so the woods is a scary place. We'll often get comments like, 'Are there wolves in your woods?' Things like that. So it's attached with things like nursery rhymes as well and tales from the past, you know - the outside is a scary place. (Interview 5)

Children's responses to entering a forest school site are set against a cultural background in which children are often told that woods are scary places, with wild animals, as depicted in many childhood stories, from traditional classics such as "Hansel and Gretel" to the more modern "The 
Gruffalo". Children are also told not to get dirty when playing outside, hence concerns are raised about outdoor play in natural environments. Further, there is a general concern about children playing alone outdoors, and the common advice that it is safer going out in a group reinforces the idea that woods are dangerous or better avoided (Malone 2007).

Forest school leaders described how the sessions enabled children to change their views from forests being dark and scary places to being places where they can have fun.

"...but by the time you've got on to the second and third session their relationship with the woodland is they see it as not a threatening place, but as a fun place. So I think that's probably one of the big things that, sort of, changes over the time: their relationship to the woodland environment is different at the end compared to what it was like at the start." (Interview 5)

Overcoming this fear of being in the woods and learning that the woods can be places where they can have fun, was something several practitioners commented on.

"children change their views from forests being dark and scary places to being places where they can have fun. I think it becomes less threatening to them." (Interview 21)

Once children understand the woods as being a place where they can have fun rather than be afraid, they can begin to relax and engage with the place. Feelings of safety (Manzo 2003) and happiness (Chawla 1992) have been identified as being significant, as well as the place being a setting for social experiences (Raymond, Brown, and Weber 2010). Thus, for those children who do fear the woods initially, overcoming the fear of being in woods is the first step in developing any sense of attachment to the place.

\section{Connection through identifying and naming things and places}


Through regular and repeated visits children learn to identify and name individual things and places in the woods. Practitioners believed this growing familiarity gives confidence to the children, and this has also been noted in early research on forest school (Massey 2005; Murray 2003; O'Brien 2005). These observations are supported by the work of Southon et al. (2017), which noted the importance of frequent visits in developing attachment to a place.

Practitioners reported that children learned to recognise and identify particular places, plants and animals. Forest school practitioners spoke of mental maps (Interview 3), and children naming special places (Interview $6)$.

"I've certainly seen an enthusiasm amongst the children with recognising the natural world around them. This delight in being able to name a bird or name a tree or, say a leaf, 'that's an elder!' you know, that kind of, just that natural ability to recognise something, want to share it with somebody else that just bubbles out of them. I think that's fantastic, and that certainly developed." (Interview 17)

\section{Developing an affinity for places and things}

With time children develop an affinity with particular things or places, so that items become "my den", the tree bearing "my tree face", "the swing tree", "the balancing tree trunk". With a growing sense of familiarity, and the development of a relationship with particular plants and places, children were more enthusiastic to return to that particular wood. Through identification, naming and association of particular places to activities, the woods became more meaningful environments (Kudryavtsev, Stedman, and Krasny 2012; Scannell and Gifford 2010).

\section{Developing a sense of ownership}


Several felt the process of naming objects and places (whether by their formal names, or in relation to their own activities ("Ashley's step" etc) provides a sense of "ownership" (Interviews 3,6,8 and 16) of the woods.

"Yeah, feeling ownership of a place is absolutely crucial towards changes in their understanding of guardianship." (Interview 6)

"they've, sort of, got a bit of ownership through, sort of, inventing names for places that l've adopted, sort of thing, as well, because the children have called a certain place something and a certain tree, or an area, or something like that, and so they've definitely made a, sort of, link with that place and they come back to it and they say, can we go here? And, can we go to this place?" (Interview 3)

\section{Developing and ethos of care for the woods}

The findings from the interviews with forest school practitioners also suggest that once children at forest school develop an interest in and engagement with the natural environment, this leads to a desire to protect it.

"sometimes when we've had children... to them, a wood is just somewhere where they pull it to pieces... other children look quite horrified at that. And then after a few sessions those children [who pull it to pieces] very quickly, sort of, learn how to act and behave around the plants and show them respect and to, sort of, look after their environment..." (Interview 4)

\section{Development of pro-environmental behaviour}

When asked about the goals of forest school, six of those interviewed specifically said that they felt the encouraging children's attachment to the forest school site was one of the goals of forest school, with some saying it was "fundamental" to forest school. Through their peer group, and supported by forest school leaders, children learn not to damage the environment, but to care for it. Furthermore, they became concerned when they saw that things had changed and if things have been damaged. This is the beginning of an ethos of care for the woods and the forest environment. "You know, they will, you know, be very angry with other people that have come in and not taken care of it" (Interview 6) 
"I've had one boy that had actually been excluded for arson and he was completely furious when he came in one day and noticed that somebody else had had a fire without having a fire in the proper place and had left a beer can there. He was completely incensed, (laughter) you know, because he felt so strongly about the place" (Interview 6)

\section{Returning to the woods}

Chawla (1992) noted that regret or distress at leaving a place was a sign of attachment to place. The ability to return to sites depends on their accessibility (public access, school grounds, and private land) and distance from school and home. However, within these limitations forest school leaders spoke of children returning to forest school sites at break times, after school and at weekends, and also in subsequent years.

"Oh, absolutely. Absolutely, they are [returning]." (Interview 6)

Practitioners described how children would speak about this, or they would leave signs of having returned: continuing to construct dens or fire circles; leaving messages for other groups; and in one case, graffiti.

i

"we used the playing field area which is opposite our school,... they go back at weekends, or they go to the park and they use it for family picnics and things like that. And I can tell when we go back, 'Oh, that den has been changed a bit', so, yeah, they use it but it is a public space." (Interview 8)

"I certainly know the year fours that have left still go because they still come over and say hello to us and leave a little message somewhere in a den." (Interview 8)

"Some of them do, because a couple of the sites are actually the school's, like their woodland garden, so they do every day, they know the woods better than me! Others of them don't go there, because they have to be bussed in, so they only go there with the Forest School. I do know that some of the public land that we use, the children take their parents there and then go and play the games with them, and then they run around the woods...." (Interview 21)

"we have reports from parents that the children have nagged them to go out and take them to all the places. And certainly when I have done parent-children groups, they go out a lot more. I don't know how long, I mean my longest experience is kind of over a six year period, and as far as I am aware, the children are going back but that is what they do in their own time, I can't really monitor." (Interview 20) 
Practitioners had differing views on whether children developed an attachment to the specific site of forest school, or woodland areas more generally.

"Yes they do develop a really close attachment to the site" (Interview 20).

"Obviously, the link with that particular place I don't think will last, though I think the idea and the ability will, sort of, transfer to other places, if you know what I mean, in the future......." (Interview 3)

\section{Conclusions}

Fostering relationships to nature and pro-environmental behaviour are key aims of outdoor environmental education (Otto and Pensini 2017) and forest education in particular (Grimm et al. 2011). While much research has been carried out on forest school there is less research on whether attendance at forest school can "foster a relationship with nature through regular personal experiences in order to develop long-term, environmentally sustainable attitudes" (FSA, 2020). Previous studies have identified this as an area which needs further research (Smith, Dunhill, and Scott 2018).

Two recent studies (Turtle, Convery, and Convery 2015) and Barrable and Booth (2020) have used questionnaires to assess children's environmental attitudes or connection to nature after forest school sessions, and the results show a positive impact of forest school. Cumming and Nash (2015) used focus groups with children as well as interviews with staff, and also noted children developing a sense of place through place attachment and place meaning. The research reported in this paper takes a different approach, by working through practitioners who have experience of working with many schools and children, over a wider range of settings. 
Thus the scale of the data collection is broader (more schools, more children) however the findings are the perceptions of forest school leaders, rather than direct studies of the children themselves, and it has not been possible to contextualise their comments through links to individual forest school settings or schools.

As they reflected on their experiences of working with multiple cohorts of children over several years, 17 out of the 20 practitioners interviewed commented on children developing a relationship with nature, with the place in the woods, an ethos of care, and pro-environmental behaviours. It is acknowledged that a limitation of the method used in this study is that it is not possible to state exactly how many children, or what proportion of the children, their comments refer to.

Figure 2 brings together and summarises the findings from this research to propose a process by which children attending forest school gradually develop a relationship with nature, attachment to the site, and proenvironmental attitudes. Through regular and repeated activities in a natural setting at forest school sessions, children learn to become more relaxed in the forest school environment, overcome any fears, have fun, connect with nature, have positive experiences, develop an affinity for the location, value nature and seek to protect it. These different ways in which children engage with nature and natural sites are echoed by other studies (Cumming and Nash 2015; Spiteri, Higgins, and Nicol 2020). Forest school provides the opportunity for children to visit natural sites frequently (as recommended by Southon et al. 2017), enjoying wooded sites with trees (as recommended by Laaksoharju and Rappe 2017; Wells and Lekies 
2006), and enjoying direct encounters with nature (Öhman and

Sandell 2016). These experiences mean that the forest school space is endowed with value as a space of fun, learning, positive memories and personal development, so becoming a specific place to which children become attached.

Figure 2. Through regular and repeated activities in a natural setting at forest school sessions children learn to overcome fear and have fun, connect with nature, develop an affinity for the location, and develop and ethos of care for the natural environment.

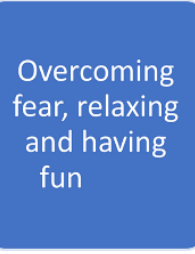
Connecting
through
identifying,
naming and
increasing
familiarity
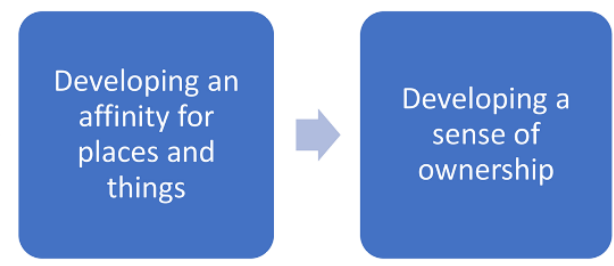

Developing

concern for

woods and

desire to protect them

The findings also indicate that for some forest school practitioners, fostering a relationship with nature and place and the development of proenvironmental behaviour in the longer term is a fundamental part of their practice of forest school. Their observation of children's activities and behaviour while at forest school suggests that there is some evidence that it is being achieved. This research has been able to highlight the factors identified by practitioners, and to consider the stages through which children progress, as they are introduced to, engage with, and become carers for, natural environments, so adding detail to the widely made assertion that time spent in nature when young will result in proenvironmental behaviours when older.

The research also shows that some of the central tenets of forest school practice are important in underpinning the opportunity to develop a relationship with nature and attachment to place: 
- the frequent and repeated nature of visits to woodlands, which allows children to return, reexplore, and become more familiar with the setting

- the importance of play and time for exploration

- child-lead learning, which enables children to follow their own interests and engage in enquiry.

The findings are echoed by other studies of environmental education in primary schools, such as Otto and Pensini's (2017) study of children in Berlin, where they found increased participation in nature-based environmental education results in greater ecological behaviour, mediated by increased connection to nature and environmental knowledge. They noted that connection to nature was more significant than increased environmental knowledge. Similarly, previous research in the UK on forest school has shown that nature engagement is a more important aspect of forest school than learning about nature (Harris 2017). Cumming and Nash (2015) noted similar processes of strong feelings of happiness and contentment, development of social connections with children and adults (staff), and development of personal connections to the place through sensory experiences in their study of forest school activities in the bush in Australia. In Canada, Elliot and Krusekopf (2018) articulated that connecting with nature and environmental stewardship were fundamental pedagogical principles within nature kindergarten, and noted the role of the environment "as another teacher". Reese (2018) identified that outdoor learning in the Children's Forests in north western USA provided opportunities which enabled the children to connect with nature. Öhman and Sandell (2016) note the importance of encouraging respect for nature which will then promote protection of nature and its conservation. 
The impact of this outdoor learning activity on environmental behaviour over the long term is yet to be fully assessed. However, this empirical research found that practitioners were aware that some children returned to sites, sometimes bringing their friends or family, but were not certain how long this would last. Forest school practitioners are aware that for some children, it may be difficult to return to the specific location of the forest school sessions. They suggested that it is also possible that children will develop an attachment to woodland areas in general, rather than the specific place at which therefore school activities have been taking place, as Harrington (2018) discusses.

The large number of studies already cited researching the potential of engagement with nature as young children on later engagement when adults highlights the importance of positive experiences in nature when young. Forest school may contribute towards this, as well as the wider aims of the children and nature movement. Further research is required to assess the longer-term impact of forest school, the length and depth of any sense of place attachment which forest school may develop, and how this may impact on children's' environmental citizenship and behaviours as they grow up.

\section{Acknowledgements}

I wish to acknowledge and thank the forest school practitioners who generously took part in interviews and shared their knowledge and experiences. I also wish to thank Richard Murray and the anonymous reviewers who made comments on the paper. 


\section{Disclosure statement}

No potential conflict of interest was reported by the authors.

\section{References}

Adams, S., and S. Savahl. 2017. "Nature as Children's Space: A

Systematic Review." The Journal of Environmental Education 48 (5): 291321. doi:10.1080/00958964.2017.1366160.

Altman, I., and S. Low. 1992. Human Behaviour and Environments: Advances in Theory and Research. Volume 12: Place Attachment, 113138. New York: Plenum Press.

Ärlemalm-Hagsér, E. 2013. "Respect for Nature-a Prescription for Developing Environmental Awareness in Preschool." Center for Educational Policy Studies Journal 3 (1): 25-44.

Barrable, A., and D. Booth. 2020. "Nature Connection in Early Childhood: A Quantitative Cross-Sectional Study." Sustainability 12 (1): 375. doi:10.3390/su12010375.

Beery, Thomas H., and Daniel Wolf-Watz. 2014. "Nature to Place: Rethinking the Environmental Connectedness Perspective." Journal of Environmental Psychology 40: 198-205. doi:10.1016/j.jenvp.2014.06.006.

Blackwell, S. 2009. Forest Schools and Outdoor Learning in the Early Years. London: Sage.

Braun, V., and V. Clarke. 2013. Successful Qualitative Research: A Practical Guide for Beginners. London: Sage. 
Chawla, L. 1992. "Childhood Place Attachments." In Place Attachments, edited by I. Altman and S. Low, 63-86. New York: Plenum Press.

Chawla, L. 2001. "Significant Life Experiences Revisited Once Again: Response to Vol. 5(4) 'Five Critical Commentaries on Significant Life Experience Research in Environmental Education." Environmental Education Research 7 (4): 451-461.

Chawla, L., and D. F. Cushing. 2007. "Education for Strategic Environmental Behaviour." Environmental Education Research 13 (4): $437-$ 452. doi:10.1080/13504620701581539.

Cheng, J. C., and M. C. Monroe. 2012. "Connection to Nature: Children's Affective Attitude toward Nature." Environment and Behavior 44 (1): 31-49. doi:10.1177/0013916510385082.

Christiansen, Ame, Siobhan Hannan, Karen Anderson, Lisa Coxon, and Doug Fargher. 2018. "Place-Based Nature Kindergarten in Victoria, Australia: No Tools, No Toys, No Art Supplies." Journal of Outdoor and Environmental Education 21 (1): 61-75. doi:10.1007/s42322-017-0001-6. Collado, S., J. A. Corraliza, H. Staats, and M. Ruiz. 2015. "Effect of Frequency and Mode of Contact with Nature on Children's Self-Reported Ecological Behaviors." Journal of Environmental Psychology 41: 65-73. doi:10.1016/j.jenvp.2014.11.001.

Cudworth, D. 2020. "Promoting an Emotional Connection to Nature and Other Animals via Forest School: Disrupting the Spaces of Neoliberal Performativity." International Journal of Sociology and Social Policy. doi:10.1108/IJSSP-09-2019-0188. 
Cumming, F., and M. Nash. 2015. "An Australian Perspective of a Forest School: Shaping a Sense of Place to Support Learning." Journal of Adventure Education and Outdoor Learning 15 (4): 296-309. doi: 10.1080/14729679.2015.1010071.

Davis, B., and S. Waite. 2005. Forest School: Opportunities and Challenges in the Early Years. Plymouth: University of Plymouth.

Elliot, E., and F. Krusekopf. 2018. "Growing a Nature Kindergarten That Can Flourish." Australian Journal of Environmental Education 34 (2): 115126. doi:10.1017/aee.2018.27.

Ernst, J., and S. Theimer. 2011. "Evaluating the Effects of Environmental Education Programming on Connectedness to Nature." Environmental Education Research 17 (5): 577-598. doi:10.1080/13504622.2011.565119.

Forest School Association. 2020. Principles and criteria for good practice https://www.forestschoolassociation.org/full-principles-and-criteriafor-good-practice/. Accessed 14 February 2020.

Gill, T. 2005. "If You Go Down to the Trees Today." The Ecologist 35 (8): 62-69.

Gosling, E., and K. J. H. Williams. 2010. "Connectedness to Nature, Place Attachment and Conservation Behaviour: Testing Connectedness Theory among Farmers." Journal of Environmental Psychology 30 (3): 298-304. doi:10.1016/j.jenvp.2010.01.005.

Grimm, A., T. Mrosek, A. Martinsohn, and A. Schulte. 2011. "Evaluation of the Non-Formal Forest Education Sector in the State of North Rhine- 
Westphalia, Germany: Organisations, Programmes and Framework Conditions." Environmental Education Research 17 (1): 19-33. doi:10.1080/13504621003602577.

Harrington, L. M. B. 2018. "Alternative and Virtual Rurality: Agriculture and the Countryside as Embodied in American Imagination." Geographical Review 108 (2): 250-273. doi:10.1111/gere.12245.

Harris, F. 2017. "The Nature of Learning at Forest School: Practitioners' Perspectives." Education 3-13 45 (2): 272-291.

doi:10.1080/03004279.2015.1078833.

Harris, F. 2018. "Outdoor Learning Spaces: The Case of Forest School." Area 50 (2): 222-231. doi:10.1111/area.12360.

Hart, R. 1994. "Children's Role in Primary Environmental Care." Childhood 2 (1-2): 92-102. doi:10.1177/090756829400200107. Hartig, T., M. Mang, and G. Evans. 1991. "Restorative Effects of Natural Environmental Experiences." Environment and Behavior 23 (1): 3-26. doi:10.1177/0013916591231001.

Holloway, S. L., and H. Pimlott-Wilson. 2014. "Enriching Children, Institutionalizing Childhood? Geographies of Play, Extracurricular Activities, and Parenting in England." Annals of the Association of American Geographers 104 (3): 613-627. doi:10.1080/00045608.2013.846167. Hunt, A., J. Burt, and D. Stewart. 2015. Monitor of Engagement with the Natural Environment: A Pilot for an Indicator of Visits to the Natural 
Environment by Children - Interim Findings from Year 1 (March 2013 to February 2014). Natural England Commissioned Reports, Number 166.

Kals, E., D. Schumacher, and L. Montada. 1999. "Emotional Affinity toward Nature as a Motivational Basis to Protect Nature." Environment and Behavior 31 (2): 178-202. doi:10.1177/00139169921972056.

Kaplan, R., and S. Kaplan. 1989. The Experience of Nature: $A$ Psychological Perspective. New York: Cambridge University Press Kellert, S. R. 2005. "Nature and Childhood Development." In Building for Life: Designing and Understanding the Human-Nature Connection, edited by S. R. Kellert, 63-89. Washington, DC: Island Press.

Kemp, N. 2020. "Views from the Staffroom: Forest School in English Primary Schools." Journal of Adventure Education and Outdoor Learning 20 (4): 369-380. doi:10.1080/14729679.2019.1697712. Knight, S. 2009. Forest School and Outdoor Learning in the Early Years. London: Sage.

Korpela, K. M., T. Hartig, F. G. Kaiser, and U. Fuhrer. 2001. "Restorative Experience and Self-Regulation in Favorite Places." Environment and Behavior 33 (4): 572-589. doi:10.1177/00139160121973133.

Kudryavtsev, A., R. C. Stedman, and M. E. Krasny. 2012. "Sense of Place in Environmental Education." Environmental Education Research 18 (2): 229-250. doi:10.1080/13504622.2011.609615. Laaksoharju, T., and E. Rappe. 2017. "Trees as Affordances for Connectedness to Place - a Framework to Facilitate Children's 
Relationship with Nature." Urban Forestry \& Urban Greening 28: 150-159. doi:10.1016/j.ufug.2017.10.004.

Leather, M. 2018. "A Critique of "Forest School" or Something Lost in Translation." Journal of Outdoor and Environmental Education 21 (1): 5-18. doi:10.1007/s42322-017-0006-1.

Lewicka, M. 2011. "Place Attachment: How Far Have We Come in the Last 40 Years?" Journal of Environmental Psychology 31 (3): 207-230. doi:10.1016/j.jenvp.2010.10.001.

Lloyd, A., S. Truong, and T. Gray. 2018. "Place-Based Outdoor Learning: More than a Drag and Drop Approach." Journal of Outdoor and Environmental Education 21 (1): 45-60. doi:10.1007/s42322-017-0002-5. Louv, R. 2005. Last Child in the Woods. New York: Algonquin Books. Lovell, R., and J. Roe. 2009. "Physical and Mental Health Benefits of Participation in Forest School." Countryside Recreation 17 (1): 20-23. Lumber, R., M. Richardson, and D. Sheffield. 2017. "Beyond Knowing Nature: Contact, Emotion, Compassion, Meaning, and Beauty Are Pathways to Nature Connection." PLoS ONE 12 (5): e0177186. doi:10.1371/journal.pone.0177186.

Malone, K. 2007. "The Bubble-Wrap Generation: Children Growing Up in Walled Gardens." Environmental Education Research 13 (4): 513-527. doi:10.1080/13504620701581612. 
Manzo, L. C. 2003. "Beyond House and Haven: Toward a Revisioning of Emotional Relationships with Places." Journal of Environmental Psychology 23 (1): 47-61. doi:10.1016/S0272-4944(02)00074-9.

Marketing, England. 2009. Report to Natural England on Childhood and Nature: A Survey on Changing Relationships with Nature across Generations. Warboys, Cambridgeshire: England Marketing. Massey, S. 2005. The Benefits of Forest School Experience for Children in Their Early Years Worcester: Worcestershire LEA.

Maynard, T. 2007. "Forest Schools in Great Britain: An Initial Exploration." Contemporary Issues in Early Childhood 8 (4): 320-331. doi:10.2304/ciec.2007.8.4.320.

Morgan, A. 2018. "Culturing the Fruits of the Forest: Realising the Multifunctional Potential of Space and Place in the Context of Woodland and/or Forest Schools." Journal of Outdoor and Environmental Education 21 (1): 117-130. doi:10.1007/s42322-017-0008-z. Morgan, P. 2010. "Towards a Developmental Theory of Place Attachment." Journal of Environmental Psychology 30 (1): 11-22. doi:10.1016/j.jenvp.2009.07.001.

Murray, R. 2003. Forest School Evaluation Project. A Study in Wales. London: New Economics Foundation.

O'Brien, Liz, and Richard Murray. 2007. "Forest School and Its Impacts on Young Children: Case Studies in Britain." Urban Forestry \& Urban Greening 6 (4): 249-265. doi:10.1016/j.ufug.2007.03.006. 
O'Brien, L. 2005. Trees and Woodlands: Nature's Health

Service. Farnham: Forest Research.

Öhman, J., and K. Sandell. 2016. "Environmental Concerns and Outdoor Studies" page 30-39 In Routledge International Handbook of Outdoor Studies, edited by B. Humberstone, H. Prince, and K.

A. Henderson. London: Routledge.

Otto, S., and P. Pensini. 2017. "Nature-Based Environmental Education of Children: Environmental Knowledge and Connectedness to Nature, Together, Are Related to Ecological Behaviour." Global Environmental Change 47, 88-94.

Palmer, J. A., J. Suggate, I. Robottom, and P. Hart. 1999. "Significant Life Experiences and Formative Influences on the Development of Adults' Environmental Awareness in the UK." Environmental Education Research 5 (2): 181-200. doi:10.1080/1350462990050205.

Pretty, J., C. Angus, M. Bain, J. Barton, V. Gladwell, R. Hine, S. Pilgrim, G. Sandercock, and M. Sellens. 2009. "Nature, Childhood, Health and Life Pathways." ICES Occasional Paper 2009-02. Colchester: University of Essex.

Raymond, C., G. Brown, and D. Weber. 2010. "The Measurement of Place Attachment: Personal, Community, and Environmental Connections." Journal of Environmental Psychology 30 (4): 422-434. doi:10.1016/j.jenvp.2010.08.002.

Reese, R. F. 2018. "Adult Stakeholder Perceptions of 4th Grade Participation in Children's Forest Environmental Education 
Programming." Environmental Education Research 24 (8): 1211-1223. doi:10.1080/13504622.2018.1471667.

RSPB. 2015. Connecting with Nature report [Online] RSPB. Accessed 14 July 2015. https://www.rspb.org.uk/Images/connecting-with-nature_tcm9354603.pdf

Scannell, L., and R. Gifford. 2010. "Defining Place Attachment: A Tripartite Organizing Framework." Journal of Environmental Psychology 30 (1): 1-10. doi:10.1016/j.jenvp.2009.09.006.

Schebella, M. F., D. Weber, K. Lindsey, and C. B. Daniels. 2017. "For the Love of Nature: Exploring the Importance of Species Diversity and MicroVariables Associated with Favorite Outdoor Places." Frontiers in Psychology 8: 2094. doi:10.3389/fpsyg.2017.02094.

Schon, D. 1983. The Reflexive Practitioner. How Professionals Think in Action. New York: Basic Books.

Sjöblom, Pia, and Lili-Ann Wolff. 2017. “It Wouldn't Be the Same without Nature"-The Value of Nature According to Finnish Upper Secondary School Students." The Journal of Environmental Education 48 (5): 322333. doi:10.1080/00958964.2017.1367637.

Smith, M. A., A. Dunhill, and G. W. Scott. 2018. "Fostering Children's Relationship with Nature Exploring the Potential of Forest School." Education 3-13 46 (5): 525-534. doi:10.1080/03004279.2017.1298644. 
Southon, G. E., A. Jorgensen, N. Dunnett, H. Hoyle, and K. L. Evans. 2017. "Biodiverse Perennial Meadows Have Aesthetic Value and Increase Residents' Perceptions of Site Quality in Urban Green Space." Landscape and Urban Planning 158: 105-118. doi:10.1016/j.landurbplan.2016.08.003.

Spiteri, J., P. Higgins, and R. Nicol. 2020. "It's like a Fruit on a Tree: Young Maltese Children's Understanding of the Environment." Early Child Development and Care : 1-17. doi:10.1080/03004430.2020.1850444.

Sustainable Development Commission. 2011. Children and Nature: $A$ Quasi-Systematic Review of the Evidence. London: Greater London Authority.

Swarbrick, N., G. Eastwood, and K. Tutton. 2004. "Self-Esteem and Successful Interaction as Part of the Forest School Project." Support for Learning 19 (3): 142-146. doi:10.1111/j.0268-2141.2004.00337.x.

Tiplady, L. S. E., and H. Menter. 2020. "Forest School for Wellbeing: An Environment in Which Young People Can 'Take What They Need." Journal of Adventure Education and Outdoor

Learning doi:10.1080/14729679.2020.1730206.

Tuan, Y. F. 1977. Space and Place: The Perspectives of Experience. Minnesota: University of Minnesota Press.

Tugurian, L. P., and S. J. Carrier. 2017. "Children's Environmental Identity and the Elementary Science Classroom." The Journal of Environmental Education 48 (3): 143-153. doi:10.1080/00958964.2016.1191415. 
Turtle, C., I. Convery, and K. Convery. 2015. "Forest Schools and Environmental Attitudes: A Case Study of Children Aged 8-11

Years." Cogent Education 2 (1): 1100103. doi:10.1080/2331186X.2015.

Waite, S., and A. Goodenough. 2018. "What is Different about Forest School? Creating a Space for an Alternative Pedagogy in England." Journal of Outdoor and Environmental Education 21 (1): 25-44. doi:10.1007/s42322-017-0005-2.

Waite, S., and A. Goodenough. 2010. "How Can We Know?: Approaches to Assessing Some 'Soft' Benefits of Woodland Activities for Children in Participative Research with the Third Sector." Paper for Children and Nature: Measuring Success? Seminar, London, October 21.

Wells, N. M., and K. S. Lekies. 2006. "Nature and the Life Course: Pathways from Childhood Nature Experiences to Adult Environmentalism." Children, Youth and Environments 16 (1): 41663. Wenger, E. 1998. Communities of Practice: Learning, Meaning and Identity. Cambridge, UK: Cambridge University Press.

White, R., and V. Stoecklin. 2008. Nurturing Children's Biophilia:

Developmentally Appropriate Environmental Education for Young Children. Collage:Resources for Early Childhood Educators, November.

Zylstra, M. J., A. T. Knight, K. J. Esler, and L. L. Le Grange. 2014. "Connectedness as a Core Conservation Concern: An Interdisciplinary Review of Theory and a Call for Practice." Springer Science Reviews 2 (12): 114-119. doi:10.1007/s40362-014-0021-3. 
